\title{
TUITION/PRICING FOR ONLINE LEARNING
}

\author{
Karen Paulson \\ National Center for Higher Education Management Systems
}

\begin{abstract}
To make online learning an integral part of higher education, institutions must determine the real costs of instruction and what tuition to charge based on these costs. Then the question is: Is this tuition bearable by the target population of potential students?
\end{abstract}

\section{KEYWORDS}

Instructional Costs, Pricing, In-State and Out-Of-State Electronic Rates, Single and Differential Tuition Rates, Discounts, Workforce

\section{INTRODUCTION}

There are two primary methods for incorporating online learning into the fabric of postsecondary education: 1) online learning as separate activity; or 2) online learning as an integral and accepted aspect of "business as usual." This paper takes the position that online learning is and should be "business as usual." Therefore, it does not address:

- How to determine the relative cost of technology-enhanced or technology-based instruction, although it is important to know this. For good techniques on how to do this see the work of the National Center for Academic Transformation (www.center.rpi.edu) and the Technology Costing Methodology Project of the Western Cooperative for Educational Telecommunications (www.wcet.info/services/tcm).

- The argument that technology should be considered part of the infrastructure of an institutionhere we assume that technology's provision, upkeep, and refreshment are included - and that there are no hidden costs, although (again) it is important to have made this case and prevailed at the institutional and state levels. For supportive material on this topic see Using Finance Policy to Reduce Barriers to Distance Learning, by the Southern Regional Education Board, August 2002 [1].

Starting from this premise - of online learning as an integral part of higher education's business as usual - this paper envisions a future in which online learning, blended learning, and face-to-face learning co-exist equitably within institutions and state systems of higher education. We now turn to the question of cost and tuition when online learning and the rest of higher education are fully integrated.

\section{BOTTOM LINE INSTRUCTIONAL COSTS}

The real cost of instruction at institutions - all undergraduate instruction including all forms of deliverymust be determined (note: specifically not delineated by delivery method). To do so all costs and activities need to be unbundled and understood in their entirety. At the same time, it is important to get a clear picture of the sources of revenue that cover these costs - tuition, state support, and the exploding number of special purpose fees.

When costs and activities are unbundled [2, 3], instructional costs include the following types of 
expenses:

- Instructor(s) salary and compensation

- Infrastructure costs (for face-to-face classes such items include light and heat for classrooms, for online education it includes electronic networks and course management system costs)

- Academic advising costs

- Curriculum development and refreshment costs (these are usually seen as a big expense for online courses, which it can be initially; however, if all courses (online and face-to-face) were to be rigorously and continuously refined to incorporate the best pedagogical techniques, much more money would be budgeted here for all forms of instruction not simply online learning)

- Delivery costs (for instance for face-to-face instruction at remote locations the costs for transporting instructors to meet with students, for online education it might include any per student costs for course management systems)

- Student academic support services (access to library, tutors, etc.)

- Administrative costs in support of undergraduate instruction (such as the president's salary, etc.)

Note that instruction and student services are usually the most expensive aspects of higher education. This holistic approach to calculating the real cost of undergraduate instruction will not result in a lower or reduced cost. In fact, it will likely alarm many people when they see what the actual cost of undergraduate instruction really is; nevertheless, without understanding total costs there is no basis - other than pure market - for establishing price (the tuition that students are asked to pay). Armed with the "new" bottom line for instructional costs at an institution or for a state system of higher education, we turn to what tuition to charge students.

\section{IN-STATE, OUT-OF-STATE, ELECTRONIC RATE?}

A question posed about tuition for online learning is: should the institution charge in-state, out-of-state, or some in-between level of tuition? The differential of in-state and out-of-state tuition for traditional postsecondary education arises from the assumption that tax-paying citizens of the state are already subsidizing public higher education through tax-supported allocations to institutions; therefore, they should carry less of the tuition burden compared to out-of-state students who presumably did not pay any taxes in the state.

Due to the ad hoc methods that some institutions have used for setting tuition, particularly for online learning, the price differences that exist confuse many students. In some cases, on-campus, in-state students must pay out-of-state tuition to take one or two online courses, even though the bulk of the student's courses are taught in a face-to-face classroom. It does not make sense to students or their parents, or even often to faculty and administrators. These price differentials are a function of old pricing practices being awkwardly adapted to new delivery modes instead of fundamentally rethinking how tuition is charged for the entire higher education enterprise.

As state support for higher education decreases, it becomes increasingly of interest why a differential tuition is still charged. One reason is because out-of-state tuition is largely "gravy" in institutional coffers. Another reason is history and that people understand the difference between in-state and out-of-state tuitions. And yet, perhaps the most compelling reason is that although state support has indeed declined, tuition still is a substantial portion (approximately 40 to 50\%) of all undergraduate instructional costs (when athletics, other auxiliary activities and research are excluded).

This paper presents two scenarios: 1) a single tuition rate for all undergraduate students that does not rely 
on differentials; and 2) differential tuition based on selected student characteristics used consistently across delivery modes.

\section{A. Single Tuition Rate}

Using the true costs of undergraduate instruction (based on the inclusion of infrastructure for all forms of delivery), a single tuition might be charged to all students-in-state, out-of-state, online, or face-to-face. This method would be analogous to private institutions that charge a single price to students, or the "erate" advocated by SREB. Currently out-of-state students pay two to four times what in-state students do on a typical public university campus. Therefore, to envision a tuition rate between what in-state and outof-state students pay, it would likely be one and a half times of what the current in-state tuition is.

Pros: This approach is simple and easily understood. It allows for incorporation of market forces. It shifts the focus of policymaking away from pricing discussions to discounting decisions, forcing attention to ways in which public funds are used to "buy down" tuition in the marketplace.

Cons: The single tuition rate could penalize in-state students because they are already supporting the institution through the tax structure if discounting mechanisms are not in place. The single tuition rate will likely be higher than current in-state rates because of the need to incorporate not only all delivery methods but all students and to recover the actual costs of undergraduate instruction. Another issue is that the single tuition rate does not allow for as much flexibility as is needed for the different policy environments in each of the fifty United States.

\section{B. Differential Tuition Based on Student Characteristics}

Another possibility would be to charge differential tuition but base it on the newly calculated true costs of undergraduate instruction (based on the inclusion of infrastructure for all forms of delivery). The student characteristics for this differential tuition might be:

1. In-State

2. Out-of-State, On-Campus

3. Out-of-State, Off-Campus

Pros: This approach is easier to understand than the current array of tuition. It is also more rational than how many institutions approach tuition for online learning and would more easily be adapted from current policies.

Cons: This version still differentiates tuition based on geography which many people think to be the antithesis of online learning.

\section{ARE THESE COSTS BEARABLE?}

After determining what the real costs of instruction are and what tuition to charge based on these costs, then the question is: is this tuition bearable by the target population of potential students? Generally, MBA programs charge more than programs for, say, family financial planning degrees because the students pursuing MBAs are able to comfortably bear the cost either due to their personal financial situation or because educational costs are borne by their employers.

One method for making costs bearable is to "buy down" from the set tuition. This "Miami of Ohio" 
method - to charge full cost with differential deductions - is of interest to many in higher education. Then, depending on the needs of the various constituencies, the tuition can be discounted or targeted financial aid can be awarded to offset the real cost of instruction. Who should do the discounting or buying down? Three entities are of primary importance here. The state would want to give discounts to students pursuing degrees that are needed in the state, for instance teacher education graduates. The institution itself may have an interest in affecting students' behavior in some cases such as Oregon State did when they charged a lower tuition for courses offered at unpopular times (early morning and evening courses); it might be that rather than starting new building construction, enrollments are encouraged in blended or online courses. And, finally, sometimes even the department might be the entity which gives the discount as some Human Sciences departments do in the Great Plain Interactive Distance Education Alliance because it is a part of their land grant mission to support county extension work in the states. Note that the discount is real money and must be recovered from real budget lines. The ability to buy down or discount is particularly attractive because of its flexibility, especially when buying down from a set tuition based on the actual cost of undergraduate instruction.

\section{SLOAN-C'S PILLARS OF SUCCESS}

How do these scenarios fit with Sloan-C's Pillars of Success for online learning?

Learning Effectiveness: Nothing in these scenarios precludes the importance of learning effectiveness. Indeed, it is hoped that by explicitly including curriculum development costs in calculating the cost of undergraduate instruction that its importance will be highlighted. And, by basing tuition on the full cost of undergraduate instruction, it might shorten time to degree by motivating students to finish once they become aware of the real costs of attending college.

Student Satisfaction: A result of moving to either a single tuition rate or a clearer use of in-state/out-ofstate, on-campus/out-of-state, off campus characteristics would be less misunderstanding of tuition on the part of students and families.

Faculty Satisfaction: Unbundling the cost of instruction for all forms of delivery (online, face-to-face, blended) would emphasize the importance of all activities for all forms of delivery (particularly in curriculum development and refinement). Furthermore, instructional salaries and compensation would be more explicit for all types of courses rather than being a hodge-podge based on whether courses taught were in-load or out-of-load, or using different delivery modes.

Cost Effectiveness: By more explicitly citing instructional costs of all forms of delivery as the total approach of an institution, it might encourage institutions to streamline activities and look for efficiencies rather than re-creating either structures or infrastructure for separate institutional functions. It eliminates the online as "other" nature of higher education.

Accessibility: The ability to more clearly see the "buy down" or discount needed to real costs in order to encourage students to either enroll in particular types of courses or in particular types of degrees would have utility.

\section{CONCLUSION}

These ideas of fundamentally changing higher education's approach to cost and tuition for undergraduate 
education include:

- Calculating the real costs of undergraduate instruction incorporating all modes of delivery

- New tuition possibilities

- A single tuition rate

- Differential tuition based on student characteristics

- "Buying down" or discounting based on market, state, institutional, departmental needs

The Sloan Consortium might consider making the case for why institutions and states should pursue these options, particularly as higher education moves forward toward making online learning part of "business as usual."

\section{ABOUT THE AUTHOR}

Karen Paulson began work at the National Center for Higher Education Management Systems as a Staff Associate in October, 1996. Prior to joining NCHEMS, she worked at the Center for the Study of Higher Education, Penn State University. At CSHE she was a member of the Evaluation Team for the NSFfunded ECSEL Engineering Education Coalition, a consortium of seven engineering institutions, since its inception in 1990. While at Penn State, she was also a member of the Steering Team for the Schreyer Institute for Innovation in Learning, an organization working toward infusing active and collaborative learning throughout undergraduate curricula.

Before moving to Pennsylvania, Karen was a Program and Policy Analyst in Academic Policy Analysis at the University of Illinois. Her education includes a B.S. in Ceramic Engineering with a minor in Bioengineering and two M.S. degrees in Metallurgical Engineering and Higher Education Administration all from the University of Illinois at Urbana-Champaign and a Ph.D. in Higher Education with a minor in Policy Analysis from Penn State University.

\section{REFERENCES}

1. Southern Regional Education Board Distance Learning Policy Laboratory Finance Subcommittee. Using Finance Policy to Reduce Barriers to Distance Learning, August 2002. http://www.ecinitiatives.org/policylab/Reports/Finance Final 9.06.pdf.

2. Paulson, K. Reconfiguring faculty roles for virtual settings. Journal of Higher Education (Special Issue: The Faculty in the New Millennium) 23(1): 123-140, 2002.

3. Jones, D. P. and F. Jewett. Procedures for calculating the costs of alternative modes of instructional delivery. In: Dollars, Distance, and Online Education: The New Economics of College Teaching and Learning, 213-238. Phoenix: The American Council on Education and The Oryx Press, 2000. 